\title{
LA REBELIÓN POPULAR DE LOS TERRAZGUEROS: ¿ETNOGÉNESIS TEMPRANA FRENTE AL COLONIALISMO ESPAÑOL?
}

ISRAEL JURADO ZAPATA ${ }^{1}$

UNAM

\begin{abstract}
RESUMEN: El proceso colonial español en lo que hoy conocemos como México propició importantes cambios sociales, políticos y económicos, donde los pueblos indígenas fueron activos partícipes de la construcción de su devenir histórico. En el caso de los pueblos nahuas del Altiplano central en particular, las antiguas propiedades de su organización social como unidades productivas o barrios denominados calpultin, que les permitían defender sus intereses colectivos, aunado a los intereses coloniales por la desintegración del poder político y económico de caciques indios y encomenderos españoles, y al creciente malestar social a causa de las crisis, económicas, políticas, sociales y demográficas que aquejaron al territorio durante todo el siglo XVI, se concatenaron para llevar a los indigenas del "común" (campesinos principalmente) a emprender la llamada "Rebelión de los terrazgueros", lucha "popular" por la reconfiguración del "pacto social", génesis de la República de Indios en la Nueva España, reinvención ontológica del ser indígena en el contexto colonial y estrategia político-económica de la colonia para establecer las bases que le llevarían a prosperar pos casi tres siglos.
\end{abstract}

PALABRAS CLAVE: etnogénesis; poder político; relaciones de producción; rebelión popular; campesinos y terrazgueros; identidad y cultura.

ABSTRACT: The Spanish colonial process in what is now known as Mexico led to important social, political and economic changes, where indigenous peoples were active participants in the construction of its historical development. In the case of the Nahua people of the Central Highlands in particular the former properties of social organization as productive units or neighborhoods called calpultin, allowing them to defend their collective interests, coupled with colonial interests by the disintegration of the political and economic power Indian caciques and "encomenderos", and growing social unrest because of the economic, political, social and demographic crisis that afflicted the territory throughout the sixteenth century, is concatenated to bring indigenous "common" (farmers mainly) take the "Revolt of the "terrazgueros", fight "popular" by the reconfiguration of the political-economic "social pact" genesis of the Republic of Indians in New Spain, ontological reinvention of being indigenous in the colonial context and strategy colony to lay the groundwork that will lead to flourish after nearly three centuries.

KEYWORDS: ethnogenesis; politic power; production relations; popular rebellion; peasants and terrazgueros; identity and culture.

\footnotetext{
${ }^{1}$ Lic. en Sociología y Mtro. en Estudios Mesoamericanos. Doctorante en Historia y Etnohistoria, Escuela Nacional de Antropología e Historia (ENAH). Docente de Sociología de las culturas indígenas, Facultad de Ciencias Políticas y Sociales (UNAM). E-mail: yancuic_qiam@yahoo.com.mx .
} 
A mediados del siglo XVI el oidor de la Real Audiencia de la muy insigne y gran ciudad de México, Doctor Alonzo de Zorita, recibió una cédula en la que se le encomendaba averiguar "algunas dudas de que $S$. M. (Su Majestad) quería ser informado”, entre ellas: “...sobre los Señores que había y tributos que les pagaban los naturales de aquellas partes (la Nueva España) en tiempos de su gentilidad y después que están en la Corona Real de Castilla".

Lo que presentó en su informe final: Breve y Sumaria Relación... fue la historia de una auténtica revolución en la que los sectores subordinados de la sociedad colonial, los que eran concebidos con los binomios lexicales (JOHANSSON, 1993): las manos y los pies, la cola y el ala, el pelo y las uñas..., del estado², que sostenían económicamente con su tributo y trabajo obligatorio a los antiguos cacicazgos, daban ahora la espalda al pacto social que les había mantenido atados a los linajes gobernantes y, operando una importante transformación de sus concepciones del mundo social, se reinventaban como colectividades valiéndose de modelos organizativos españoles.

Con esto haremos la revisión de un capítulo poco conocido en la historia de los pueblos indígenas de México, y reflexionaremos sobre el posible proceso de etnogénesis ${ }^{3}$ que representó para estas colectividades su propia reinventaron ante la catástrofe demográfica, social, política y económica que significó el inicio de la colonización española, pues como observó el propio Zorita en la incierta tasa del tributo: “...se anda variando (...) parece injusto que tributen todo cuanto pueden, porque parece más de esclavos que de hombres libres, y contra la intención de S. M." (ZORITA, 1941).

\footnotetext{
${ }^{2}$ Estas figuras gramaticales son ampliamente utilizadas en documentos coloniales en lengua náhuatl (huehuetlahtolli, en fuentes como la Historia tolteca chichimeca, en cantos e himnos sacros, etc.) para referirse a abstracciones conceptuales. De éstas las más conocidas son: in xochitl, in ciucatl-para referirse a la poesía; al-tépetl-para referirse a la ciudad y territorio; y los que nos atañen aquí que refieren al "pueblo", a la "comunidad": in itconi, in mamaloni-el que puede ser portado, el que puede ser cargado; in cuitlapilli, in atlapalli-la cola, el ala; in ima in icxi-su mano, su pie.

${ }^{3}$ Este concepto será entendido como lo plantean Bartolomé (2003) y Hill (1996) citado por Good y Corona (2011).
} 


\section{Conceptos analíticos (poder político y etnogénesis)}

Tras la reconfiguración del poder en el Altiplano central mesoamericano (cuenca lacustre de Anáhuac) con la llegada de los españoles, siguió la reestructuración de las relaciones sociales de producción básicas entre comunidades tributarias y grupos sociales privilegiados indígenas, detentores del poder político, a través del cual ejercían el poder económico, se apropiaban de la producción y controlaban la fuerza de trabajo de los macehualtin (castellanizado: maceguales), y de los "terrazgueros"4, dentro de los cuales se agrupaban campesinos, artesanos, trabajadores manuales y de oficios no prestigiosos, comerciantes $y$, en general, todos aquellos que estaban incluidos en los mencionados binomios léxicos referentes a la población en general o el común.

La destrucción de México-Tenochtitlan no significó el fin del poderío político de los antiguos tlatoque (plural de tlahtohuani- "el que habla", supremo gobernante o rey: MOLINA, 2008), aunque sí su disminución acompañada del reacomodo de tierras de tributo, tributarios y terrazgueros, y tasas de tributo; donde los españoles con la figura del encomendero pasarían a formar parte del sector social extractor de la producción y detentor del poder político para las tasaciones.

El poder de caciques y encomenderos asociado a dominación y subordinación puede entenderse como "la capacidad de actuar efectivamente sobre las personas y las cosas, recurriendo a una gama de medios que se extienden desde la persuasión hasta la coerción" (SMITH, apud BALANDIER, 2004, p. 105). Es una "categoría particular de

\footnotetext{
${ }^{4}$ Aparecieron nominalmente en el valle de México, Toluca, Puebla, Chalco, Tlaxcala y Oaxaca según Menegus (2005), quien señala que su número fue menor al de la población mayoritaria de maceguales asentados en calpulli y con acceso directo a la tierra en la cuenca lacustre de México; pero en el valle Puebla-Tlaxcala fue todo lo contrario. William Taylor citad por Menegus (2005) los define como "habitantes de las tierras del cacicazgo". Heriberto Martínez citado por Menegus (2005), dice que en su mayoría eran labradores, pero también había artesanos, cazadores y mercaderes. Sus rasgos más destacados eran ser fuerza de trabajo carente de tierras, no pagar tributos al rey y no estar obligados a cumplir cuotas de repartimiento de mano de obra ya en el periodo colonial (MENEGUS, 2005). Estaban diferenciados de los maceguales, pero pronto se compartieron los mismos intereses. Castro Gutiérrez (2004) los define en la provincia de Michoacán como "todos los habitantes de los pueblos sujetos a la autoridad del cazonci o bien solamente los llamados curintziecha que ocupaban y trabajaban las tierras patrimoniales de los nobles".
} 
relaciones sociales; implica la posibilidad de obligar a los "otros" en un sistema de relaciones entre individuos y entre grupos." (BEATTIE apud BALANDIER, 2004, p. 105).

Entendido así, vino acompañado de contradicciones, pues la mayor desigualdad social que provocó, incentivó la oposición. A mayor desarrollo del poder menor fue su legitimidad y el consentimiento del resto de la comunidad, reduciendo con ello su influencia (GLUCKMAN apud BALANDIER, 2004, p. 171); clave del fenómeno del que se tratará aquí, pauta para la rebelión.

Rebelión es entonces la persistencia de una identidad regional distintiva, con sus propias lógicas productivas, culturales y comunitarias. La necesidad de separar a las dos grandes poblaciones coloniales (indígenas y españoles), vino a marcar aún más las percepciones de la diferencia entre éstas, y entre los primeros y sus antiguos linajes gobernantes, que cada vez más se identificaban en la educación y prácticas culturales con los segundos.

Desde esta perspectiva, etnogénesis está asociado a la búsqueda de la preservación, mantenimiento y desarrollo de las formas culturales y lingüísticas, a la reafirmación étnica en un contexto de adversidad política. Y precisamente la política indigenista colonial favorecería tales formas de reafirmación bajo el velo evangelizador.

También al reclamo repentino y estrepitoso de derechos políticos y culturales, y no como el resultado de migraciones, invasiones o fusiones que configuran colectividades (como tradicionalmente ha sido definida), cobrando sentido en nuestro contexto al asociarse al surgimiento de nuevas comunidades que se designan a sí mismas en términos étnicos para diferenciarse de otras sociedades (BARTOLOMÉ, 2003 , p. 174) cuando la creación de las Repúblicas de Indios, antecedente inmediato en lo político y económico de los actuales pueblos indígenas de México.

En su acepción de proceso de creación y adaptación en búsqueda de la supervivencia de un grupo como tal, ligado a la conciencia histórica que éste tiene de sí mismo, de su lucha para persistir en un contexto de cambio radical en el contexto de la expansión de los estados coloniales (HILL, 1996, apud GOOD y CORONA, 2011 , p. 29), la etnogénesis considerada aquí con su "visión ampliada" del tradicional 
campo significativo, permite la exploración de las interrelaciones locales de vasallaje de los indios de México con la colonia española (HILL, 1996, apud GOOD y CORONA, 2011 , p. 29).

\section{(Cultura, identidad)}

La identidad en los últimos dos siglos de la época precolombina se basaba según las propias fuentes secundarias en el calpulli, en la entidad sagrada calpu/teot/5, en la etnonímia, en las prácticas culturales y en la lengua (LÓPEZ AUSTIN, 1980). La dimensión de yuhcatiliztliforma de ser, vivir, sentir, pensar y reproducir la cultura (LEÓNPORTILLA, 1980 y 2006) resulta un concepto abstracto también asociado a lo que hoy entenderíamos por cultura e identidad.

En cuanto a cultura y organización social, según aquellas fuentes secundarias (Crónicas de Indias, anales y genealogías coloniales) podemos considerar diferentes niveles de organización social. Primero están los grupos de parentesco que Morgan y Taylor denominaron "clanes", pero más tarde fueron definidos como grupos ambilaterales con tendencia a la endogamia (MONZÓN apud CARRASCO, 1982), con características de unidad económica autónoma fundamental, a la que se le atribuyen ciertas actividades, de ahí su valor para la unidad política mayor o altépet/6.

Calpulli como unidad productiva y de parentesco primero, y altépet/ como unidad política mayor después, a la que se adscribían varios calpoltin (plural de calpulli), encerraba una gran diversidad, pues podía contener hablantes de diferentes lenguas que se aglutinaban en torno a un poder político central, conformado por una estructura noble de burócratas y sacerdotes en el centro religioso y administrativo del altépet/. Pero nos remitiremos a dibujar sólo esta dimensión de cómo se cree hasta hoy por algunos investigadores, se entendían aquellas sociedades.

Las colectividades indígenas en tiempos precolombinos eran pues,

\footnotetext{
${ }^{5}$ De calpulli-barrio y teotl-divinidad: calpulteotl-la divinidad del barrio, divinidad patronal del calpulli.

${ }^{6} \mathrm{El}$ altépetl, difrasismo: atl-agua/tépetl-cerro, hace referencia a la unidad política mayor o "Estado" según Federico Navarrete y Alfredo (2011) y López Austin (1980).
} 
multiétnicas y multilingües, pero en el periodo colonial temprano $(1536-1600)^{7}$, con el sistema de congregaciones, los reacomodos poblacionales, las migraciones de colonización septentrional, la defunción masiva, y la política de la congregación, la población indígena sufriría un importante shock colectivo.

Reponiéndose de aquel shock, en una operación de resistencia, adaptaron instituciones hispanas como el cabildo y la propiedad colectiva de la tierra jurídicamente regulada 8 , impulsados y auspiciados por las propias autoridades coloniales, logrando sobrevivir a la época, a los españoles y a sus antiguos linajes gobernantes, al reinventarse en una adaptación cultural que dio como resultado a los pueblos y comunidades indígenas como les conocemos hoy.

\section{(Rebelión popular)}

Entenderemos lo "popular" desde la perspectiva de Néstor García Canclini, como ese elemento socioeconómico integrado por los sectores subalternos de la sociedad, que buscan reivindicar sus propias demandas frente a las condiciones de marginalidad y exclusión política, contrapuestos en diversos niveles organizativos, a las "clases" dominantes, detentoras de una "cultura dominante" (CANCLINI NESTOR, 2004, p. 153-155). Y trasciende aquí la dimensión de lo "popular" porque la propia época en cuestión nos marca el punto de convergencia como ecuánime equivalencia.

Presente en el vocabulario de los frailes cronistas del siglo XVI novohispano, lo "popular" hace referencia a los vasallos, gente pobre, gente sin lustre, campesinos y artesanos en general, bajo el yugo y obediencia hacia sus autoridades civiles, eclesiales y monárquicas; puente semántico que le asocia a nuestro concepto actual, aún en el marco de una sociedad preindustrial.

\footnotetext{
${ }^{7} 1536$ es el inicio del Virreinato y aproximadamente el 1600 es el punto más bajo del declive poblacional indígena.

${ }^{8}$ En tiempos precolombinos, al menos entre los nahuas del Altiplano central, la ocupación y usufructo de la tierra eran colectivas, pero la potestad de la tierra era del estado, del tlatocayotl-tribunal y sede del gobierno según Carrasco (1996), que junto con los macehualtin conformaban el altépetl-agua/cerrounidad política territorial.
} 
El famoso funcionario novohispano Alonso de Zorita también lo incorporó en sus discursos y, es precisamente él quién da a conocer un fenómeno de crucial trascendencia para la historia novohispana temprana: la llamada "rebelión de los terrazgueros"9, fenómeno que aquí trataremos de caracterizar como una "rebelión popular".

En cuanto a "rebelión popular", Felipe Castro Gutiérrez (1996) para la época prehispánica y colonial, Friedrich Katz (1998) para la "gran rebelión campesina de 1519-1521" en el Altiplano central y otras coloniales, y Leticia Reina (1983) cubriendo el siglo XIX mexicano, han coincidió en una tipificación de los movimientos de lucha y resistencia de campesinos e indígenas según su magnitud, duración, tipo de organización, demandas y objetivos, programa, alcance y envergadura, a saber: tumulto, motín, levantamiento, alzamiento, revuelta, rebelión, etc., las cuáles pueden ser consideradas como diferentes niveles de lucha. No nos casaremos con alguno en particular pero considero que aquí tienen mucho que ver el alzamiento y rebelión ${ }^{10}$.

\section{La rebelión de los terrazgueros}

En los últimos años de la época prehispánica, la región central de lo que hoy es Ilamado México estuvo llena de conflictos armados y crisis hegemónicas que disminuirían dramáticamente con el establecimiento del dominio colonial cimentado en alianza con los grupos dirigentes indígenas triunfantes de la guerra de 1519-1521 y la nobleza hereditaria indígena en general.

No obstante, la defunción masiva que aquejó profundamente a la población aborigen por las epidemias, reforzada por las sucesivas campañas militares fuera de la Meseta central y la explotación laboral de que fueron objeto los indios del "común", condujo a una sistemática pauperización indígena, y sentó las bases para nuevas crisis en la ya de

\footnotetext{
${ }^{9}$ Castro Gutiérrez (2004) es quien propone esta denominación a la pérdida del control sobre la fuerza de trabajo y de los medios de producción que en la provincia de Michoacán, y en general en toda Mesoamérica de forma paulatina, tuvieron los antiguos linajes gobernantes frente al advenimiento de la jurisdicción real española.

${ }_{10}$ Para saber las características fundamentales de cada tipificación ver las obras de los autores mencionados.
} 
por sí golpeada y violentada región.

Si bien los conflictos armados más serios en la naciente colonia se desplazaban poco a poco hacia las regiones fronterizas de lo que hasta entonces reclamaba la corona hispana, en la Meseta central principalmente, los "cacicazgos" atravesaron por profundas transformaciones en las relaciones sociales de producción, sobre todo, después de las reformas de Felipe II y sus Leyes Nuevas, que buscaban el desvanecimiento del poder de las antiguas élites indígenas y de los encomenderos.

Con ello, la colonización española dio inicio el declive del poder ancestral de los linajes gobernantes. Su dominio y jurisdicción fue reducida a la figura de cabeceras que se relacionaba directamente con sus sujetos en cuanto a lo económico, lo cual resultaría transicional hacia el modelo de gobierno municipal español (GIBSON, 2007, p. 168).

La destrucción de la mayoría de los antiguos altépet//tlahtocáyot/ll daría paso al nacimiento de las llamadas Repúblicas de Indios con la emancipación popular, que en un principio liberó a los indios del "común" de las pesadas cargas tributarias y demás vejaciones de que ya eran objeto para la segunda mitad del siglo XVI, por servir y pagar tributos a sus señores naturales, a los encomenderos y a las autoridades eclesiales ${ }^{12}$. Pero hay que considerar algunos otros factores de tipo político.

La encomienda como el sistema de explotación más severo de la Nueva España, que tenía una posición de poder, impuesta tempranamente, fue legitimada por Hernán Cortés, quien planteaba que

\footnotetext{
${ }^{11}$ Antigua entidad política prehispánica designada por el difrasismo altépetl-agua/cerro y tlahtocáyotltribunal de gobierno. Se designaba de una o de otra forma al estado prehispánico pero yo acostumbro conjuntarlos para el mismo efecto.

${ }^{12}$ Su creación está íntimamente ligada con la restricción progresiva del poder político y jurisdiccional de los señores naturales, que en mancuerna con la llamada jurisdicción real, que son todas las tierras e instituciones susceptibles de las disposiciones coloniales, y controladas y reguladas por éstas, así como en obligación y dependencia política y económica hacia la Corona. De esta forma, "Ganada" la Nueva España y adjudicadas las tierras y patrimonio de Moteuhczoma a la Corona Real de Castilla, la manera de gobierno que tenían los naturales organizados en los demás tlatocáyotl como Tetzcoco y Tlacupan, y otras entidades políticas sujetas o no al excan tlatoloyan (triple alianza), continuó por algunos años, con la posesión, mando y gobierno en manos de las antiguas élites prehispánicas, aunque reconocían por cabeza a S.M. y a sus representantes los encomenderos, a quienes habían entregado algunas tierras y trabajo de sus vasallos. Así, tanto su posición social como su jerarquía permanecieron con vigor algunos años más después de 1521, tiempo en el que jugaban un papel crucial para resolver necesidades prácticas de la administración colonial, como el proceso de evangelización masiva, haciendo directa o indirectamente válido su "derecho natural" hereditario. Pero pronto comenzó la carrera por la adquisición del estatus de "cabecera" ante el acotamiento y disminución de la antigua jurisdicción precolombina.
} 
con este sistema liberaría a los naturales de sus gobernantes indígenas. Más tarde, surgió para la corona la urgencia de acotar el poder de los encomenderos, para lo cual creó mecanismos mediante los que se podía perder la encomienda fácilmente, por ejemplo, por la extensión de la autoridad del encomendero a otros territorios, abuso en el cobro de tributos o maltrato a los naturales, excesos dentro de la encomienda para todo lo cual se prestaban facilidades legales a los indígenas.

No obstante, la noticia sobre las vejaciones y abusos de que eran objeto los naturales en las encomiendas no son nuevas para nadie, los encomenderos hacían toda clase de negocios con sus tributos y con su fuerza laboral. La coacción y los malos tratos, los cobros excesivos y el uso extenuante de la mano de obra en todo tipo de labores eran prácticas cotidianas.

La década de 1550 aparece como el periodo en que el poder de los encomenderos comenzó a debilitarse y en que las comunidades indígenas lograron ejercer una acción según el derecho español. Con la aplicación de las Leyes Nuevas, se buscó incorporar a los terrazgueros a los padrones tributarios reales dotándoles de tierras, proceso llevado a cabo por las congregaciones. (MENEGUS, 2005, p. 31). Por si fuese poco, los terrazgueros, patrimonio de los caciques, se perdería por las reformas del visitador Valderrama, quien elevó los tributos para disminuir el número de nobles exentos de éste, liberar a los terrazgueros de su poder, y canalizar la riqueza y beneficios gratuitos que generaban (los terrazgueros) al redil del rey (MACHUCA, apud MENEGUS, 2007, p. 175).

Con la asignación de medios de producción para aquella fuerza de trabajo, "los conflictos entre los caciques y los terrazgueros se agudizarían por falta de tierras y por la carga que representaba el pago del terrazgo para los naturales" (MENEGUS, 2007, p. 34).

En su Breve y Sumaria Relación..., Zorita daría cuenta de los conflictos desatados en aquel contexto, en el que las usurpaciones de tierras en litigios amañados por parte de encomenderos y autoridades coloniales, abonarían más al descontento social y, según versiones de algunos funcionarios coloniales, al "alzamiento armado de los indígenas del común", quienes se apaciguaban sólo hasta que la corona les resolvía con el reparo del agravio y con la tasación de los tributos. 
Las demandas de maceguales y terrazgueros, como se dijo, fueron apoyadas y hasta fomentadas por las autoridades coloniales. Así, en un principio, con la formación de los cabildos indígenas, oscura etapa colonial que se fue adaptando a las circunstancias regionales y peculiaridades étnicas, se dio paulatinamente la introducción desde épocas muy tempranas de "justicias" indígenas y otros oficiales de "república" en los cacicazgos, que fortalecerían el proceso; pero fue hasta 1550 en que se integró propiamente el cabildo, para sentar las bases de la reorganización de la tierra y a la reubicación de los asentamientos poblacionales (MENEGUS, 2007, p. 76).

La controversia sobre la conservación de las formas de gobierno indígenas y los privilegios señoriales de los tectecuhtin ${ }^{13}$, problema entre el señorío jurisdiccional y el señorío territorial, tuvo diversas opiniones encontradas entre las autoridades coloniales, en que la salvación de las almas mediante el bautizo indígena y la preservación del proyecto de evangelización frente a los señores indígenas, poco confiables por el poder que mantenían, era la fuente del debate.

Pero en la aplicación cabal de las Leyes Nuevas el común de los indígenas encontró un marco jurídico que los amparara. De esta forma, un primer golpe al poder de los señores naturales lo dio el Virrey don Antonio de Mendoza, consolidando la jurisdicción real en la Nueva España y eliminando a los señoríos que de una u otra forma se opusieran al proyecto evangelizador, así como introduciendo en las comunidades indígenas a los "justicias", nombrados de entre los indios el común.

Con el nombramiento de corregidores españoles también se afectó al señorío indígena, haciéndole perder jurisdicción sobre los naturales. La introducción de otras figuras que procuraban la justicia y protección de los "maceguales" y terrazgueros, como los alguaciles, comenzaron a sembrar en el común la idea de una "libertad" bajo las nuevas estructuras jurídicas, sin la sujeción tradicional que hasta entonces "habían padecido". La introducción en los señoríos de cargos otorgados a indígenas que no fuesen "tecles" (teuhct/l), también estuvo ligado a un proceso de delimitación de tierras y a la definición de la jurisdicción tributaria.

${ }^{13}$ Plural de teuhctli-señor natural o cacique. 
El tránsito hacia las formas de gobierno hispanas incitaba a los indígenas propensos a cosas públicas a participar en reuniones de cabildo y aprender los modos occidentales de gobierno, acelerando la propagación de estas ideas. Ello rompió, a partir de la elección democrática del pueblo de sus propias autoridades, con el sistema de sujeción por linaje; lo que fue un proceso multiforme como el caso de Tezcoco, donde prevaleció por algunos años un "gobernadoyotl"14 que a su vez era señor natural con derechos ancestrales de linaje; hasta que la intervención virreinal propició el tránsito hacia gobernadores extraídos de la clase dirigente pero sin aspiraciones señoriales (GIBSON, 2007, p. 95)15.

Como resultado de lo anterior y como parte de la política indigenista colonial que buscaba la separación de indígenas y españoles, fue la génesis de las Repúblicas de Indios, atendiendo a móviles de promoción de una "vida civil, ordenada y cristiana" entre los primeros. Así, bajo el velo libertad y bienestar para los indígenas, se encubría la necesidad de trastocar los antiguos cimientos políticos y culturales de las comunidades para, junto con los pueblos devastados y desintegrados demográficamente por epidemias y guerras, fortalecer los nuevas esquemas de organización social.

La pericia de agentes sin tierra como los antiguos mayeque ${ }^{16}$, o españoles, negros, mulatos y mestizos que buscaban el tránsito de la tierra de un marco jurídico antiguo a otro en que se pudiera enajenar o por lo menos mejor aprovechar bajo las nuevas exigencias económicas y comerciales, terminó por desatar la pugna al interior de las comunidades entre macehualtin 17 y antiguos linajes gobernantes, donde los primeros se favorecieron de la transición administrativa colonial. El

\footnotetext{
${ }^{14}$ En este nuevo orden colonial, el estatus jurídico y político de los antiguos tlatoque comenzó a transitar hacia el de "gobernadoryotl" (gobernador), más propio de la organización hispana, que a su vez les ponía en vulnerabilidad política y económica, pues como lo señaló Zorita, con diversas causas o bajo diversos pretextos les fue removido el cargo con el amparo de la legislación vigente, perdiendo el estatus social privilegiado.

${ }^{15} \mathrm{Al}$ contrario, en el caso de Tepeaca, Hildeberto Martínez demuestra la continuidad del sistema anterior al colonial, en que sus dirigentes supieron adaptar la estructura de poder a las nuevas instituciones coloniales (HILDEBERTO MARTÍNEZ, apud MENEGUS, 2007, p. 96). En el valle de Toluca, la ruptura del gobierno con los tlatoque se caracterizó por la participación de gente de origen "macegual" en el cabildo.

${ }^{16}$ Plural de maye, antiguo grupo económico de la época prehispánica que no pertenecían a ningún calpulli y que constituían una mano de obra fluctuante, sujeta a la renta de su fuera productiva.

${ }^{17}$ Plural de macehualli- vasallo, gente del común, gente pobre o popular según Molina, Sahagún y otros.
} 
tránsito de los "cacicazgos" hacia la "república", descentralizó la autoridad indígena 18 .

Otro factor que vino a trastocar de manera definitiva lo que quedaba del antiguo orden social precolombino fue la pauperización, empobrecimiento y pérdida de privilegios sistemática que padeció la antigua nobleza indígena, que junto con el colapso de la población en general, el despojo de recursos naturales, la mala alimentación, la destrucción de las tierras de cultivo a causa de la llegada del ganado y el shock anímico y trauma colectivo provocado por las guerras de conquista y la nueva situación de opresión que, incluso, inhibía la reproducción humana; desembocó en una merma cuantitativa de efectos devastadores sobre la fuerza económica del orbe.

En medio de ello, la "rebelión de los terrazgueros" daría inicio con la crisis como contexto:

Esta gente en común en todas las indias se va disminuyendo y acabando, (...); y en viéndose afligidos por el tributo ó por no poderse sustentar á sí é á sus mujeres e hijos, muy fácilmente los dejan, aunque los aman en gran manera, y dejan perdidas sus casillas y haciendillas, que todo es poco y muy miserable, y se van á otras partes, y andan vagando de unas en otras, ó se meten en los montes, donde los comen los tigres y otras fieras, y algunos se han ahorcado de desesperados, por la gran aflicción que tenían con los tributos y cobranza de ellos... (ZORITA, 1941, p. 81) ${ }^{19}$.

De manera indolente los encomenderos siguieron molestando cada vez más a los Señores naturales con el pago del tributo, sin importar el estado paupérrimo en que comenzaban a caer éstos y sus señoríos, ni las excesivas jornadas laborales a que habían quedado sometidos los terrazgueros, renteros y patrimonios (tipos jurídicos de

\footnotetext{
${ }^{18}$ La población indígena del "común" que había conquistado su libertad de un pesado yugo tributario luchando para derrocar al excan tlatoloyan, parecía en un principio no mostrar descontento con su realidad objetiva colonial, ni estar inclinada a sublevarse a la hegemonía extranjera (KATZ, 1998, p. 78). Pero la rebelión de los terrazgueros con sus importantes implicaciones socioculturales implica el tránsito de un mundo que había prevalecido durante siglos hacia una nueva realidad a la que estos sectores de la sociedad tuvieron que adaptarse para sobrevivir como colectividad.

${ }^{19}$ Zorita (1941, p. 81), menciona que había oficiales de S.M. en los pueblos, que cobraban los tributos para los encomenderos y eran los "Señores" (tlatoque), quienes se los entregaban de mano, con lo que conservaban su "gravedad y autoridad antigua", obedecidos de sus súbditos, que "los servían en modo e a manera antigua", con tributos y servicios.
} 
indígenas trabajadores) ${ }^{20}$.

Ante tales situaciones, una creciente desobediencia de los súbditos indígenas hacia sus señores comenzó a gestarse ${ }^{21}$. Zorita añade que este estado de cosas, y más aún, el "robo con mano dura" que sufrían los indios del "común", se debía a la abundancia de alcaldes y regidores, alguaciles y fiscales, y porque "no había quien se los impidiera", por lo que sugería fuesen quitados pues "no sirven más que de robar y molestar al común, y hacerse á holgar y á no tributar" (ZORITA, 1941, p. 93).

Tanto colonizadores como antiguos linajes gobernantes pelearon entonces por la fuerza de trabajo, exprimiéndola y llevando las relaciones sociales de producción a condiciones inusitadas hasta entonces, trastocando con ello el antiguo pacto social, pues en los albores del orden colonial, eran los señores naturales los que organizaban el trabajo para la propia economía de autosuficiencia de la comunidad; y después, para el servicio y tributo que debían a los nuevos grupos hegemónicos (encomenderos y autoridades coloniales), siempre proporcionalmente al tamaño, posibilidad y calidad de cada pueblo de los de su jurisdicción; razón por la que el nuevo orden no había sido difícil de aceptar en un principio por las comunidades, y todos habían quedado en paz y sosiego inicialmente.

La competencia colonial por los factores de la producción posibilitó que cualquier peninsular que ambicionara tierras e indígenas terrazgueros que las trabajasen las obtuviera por las vías del litigio o el despojo; incluso algunos religiosos aprovechando su influencia y figura de autoridad ante los señores naturales, solicitaron, con el beneplácito del propio virrey y de "otras personas letradas y doctas", ser

\footnotetext{
${ }^{20}$ El informe de Zorita gira alrededor de la conveniencia de mantener el "orden y concierto" prehispánicos de los indígenas y restituir la dirigencia política y social a sus originales detentores; lo cual era menester al contrastarse con el "desorden" y grave afectación que el orbe indiano presentaba durante sus pesquisas como visitador, derivado en gran medida de las reformas emprendidas por Felipe II y de la codicia y atropellos de los europeos, que habían desatado lo que él mismo cataloga como "plagas" evocando la destructividad de aquellas que azotaron Egipto en tiempos bíblicos.

${ }^{21}$ Esto último se vio influenciado por el hecho de que los encomenderos "abatían y deshacían" por su propia autoridad a los señores porque éstos no se sometían a su voluntad en lo tocante a los tributos y servicios personales, poniendo en su lugar a un "macehual que no hacía más que lo que ellos querían". Lo mismo ejecutaron los oficiales "calpisques" que los primeros tenían en los pueblos para organizar la recolección del tributo, el servicio diario de la gente, su envío a las minas y la renta de las tierras. Otro problema importante fue la existencia de alcaldes mayores y corregidores, tenientes y alguaciles españoles en los pueblos indígenas, que tenían la jurisdicción civil y criminal (ZORITA, 1941, p. 93).
} 
beneficiados con parte del tributo que los terrazgueros ya pagaban a los encomenderos, lo cual se generalizó como ordenanza para todos los señores de la tierra (ZORITA, 1941, p. 94).

Todo ello fue "causa de su desasosiego (de los indígenas) y de se abatir y destruir del todo los señores naturales", porque a partir de tales imposiciones, los súbditos y vasallos tomaron ocasión para comenzar a quejarse de sus señores, "...é á decir que no cumplían ni guardaban lo que con ellos había quedado concertado y se les había mandado..." (ZORITA, 1941, p. 94), tributos y responsabilidades que se habían establecido con los pueblos y comunidades en el "pacto colonial".

El conflicto al interior de las comunidades y el desasosiego popular por las pesadas cargas tributarias y de servicio, fue el contexto idóneo para que aquellos agentes españoles, mestizos y mulatos influyeran en los sectores más expoliados, incitándoles a la revuelta para levantarlos en contra de sus Señores, de lo cual obtendrían beneficios económicos pues, "les chupaban la sangre", mientras la crisis comunitaria perdía a los Señores "en lo espiritual é temporal". La confrontación con los colonizadores también se dio a través de los "procuradores", que podían constituir una especie de "picapleitos" a quienes les convenía promover litigios entre indígenas y autoridades coloniales 22 .

Entonces los súbditos comenzaron a "perseguir" a sus Señores

...y de aquí comenzaron los pleitos de unos contra otros dentro en sus pueblos, y los súbditos con los Señores en toda la Nueva España, y pueblos contra pueblos, é los subjetos contra sus cabeceras, de que han sucedido grandísimos gastos, gran multitud de muertos por los caminos, yendo y viniendo á los pleitos, sin saber lo que les conviene, ni qué piden, ni qué quieren, ni qué pretenden, ni sobre qué pelean, ni a qué van a la Audiencia..." (ZORITA, 1941, p. 95) 23.

\footnotetext{
${ }^{22}$ Anteriormente, durante los primeros años de la colonia, ya se comenzaba a dar una suerte de despojo de tierras a las comunidades, pues los españoles solicitaban tierras vacas o no cultivadas, aunque éstas sí estuviesen trabajadas; y para conseguirlas argumentaban, entre otras cosas, "que los indígenas las habían sembrado maliciosamente ante su solicitud". Jueces y funcionarios que favorecían en todo a los españoles también tenían mucho que ver en éstos despojos. A partir de ello se circunscribe el interés de españoles, mestizos y mulatos por incidir en la disolución del régimen señorial y su jurisdicción sobre la tierra, y por instigar a los súbditos para comenzar a levantarse en contra del antiguo régimen.

${ }^{23}$ Zorita (1941, p. 95) continúa la cita: “...han muerto Señores y principales y mucha gente común, hombres y mujeres, y muchachos, que van siempre con ellos á les llevar lo necesario para su sustento. Han sido muchos Señores y principales y macehuales sentenciados á minas é á obras públicas é se han
} 
A lo que añade Zorita: "no hay en toda la Nueva España cosa concertada entre ellos, por haber perdido el común la vergüenza á sus Señores y principales, y por se haber levantado contra ellos..." (ZORITA, 1941, p. 95), lo cual constituyó un fenómeno de ruptura con parte de la antigua cosmovisión que les hacía tener como autoridad a aquellos intermediarios ante la voluntad divina.

El fenómeno trastocó un aspecto medular en las relaciones de subordinación: los mecanismos que aseguran el consentimiento del gobierno, relacionados por supuesto con lo sagrado, que perturbados con el orden colonial y sus dogmas, provocaron la ruptura en el sistema tradicional, razón por la cual las antiguas figuras de autoridad se vieron progresivamente obligadas a ejercer un poder más arbitrario, aunque limitado. De ahí que los gobernados comenzaron a acudir ante las autoridades coloniales con el fin de oponerse o quejarse de sus autoridades tradicionales (FALLERS apud BALANDIER, 2004, p. 252$253)^{24}$.

La desacralización del poder encarnado en los antiguos linajes gobernantes y la invalidación de algunas de las viejas concepciones del orden social y universal, vino a sacudir desde sus cimientos las superestructuras sociales, políticas y los antiguos valores, todo ello enmarcado por una "laicización" del dominio político que neutralizaba cualquier intento de re-sacralización del poder y de sus principales símbolos (FALLERS apud BALANDIER, 2004, p. 255).

Aprovechando el desorden y bajo las nuevas estructuras de

quedado por allá muertos ó perdidos é olvidados de sus mujeres e hijos. Han sucedido grandes revueltas por esto en sus pueblos y provincias, y muy gran confusión en todo. Hanse empobrecido, destruido é gastado los Señores y el común: han venido todos en general en gran disminución, así en los espiritual como en lo temporal".

${ }^{24}$ Otro factor de suma importancia que vino a abonar en la ruina del antiguo sistema fue la caída del prestigio de los gobernantes tradicionales debido a su subordinación colonial, al carácter condicional de su poder y al a su debilitamiento económico. Ello fue acompañado del disfuncionamiento de los instrumentos tradicionales que contenían y regulaban el poder, a partir de lo cual, se constituye una élite burocratizada de cultura mestizada que progresivamente invalidó la antigua organización. Según Máx Weber la colonización provoca un proceso de tránsito de una autoridad tradicional "patrimonial" hacia una autoridad de tipo burocrático, a partir de la coexistencia incompatible del antiguo sistema tradicional y de un sistema que el autor clásico llama "moderno"; en donde los subordinados desarrollan una doble relación dirigiéndose a uno u otro sistema dependiendo la coyuntura y los intereses implicados (BALANDIER, 2004). 
pensamiento y de conducta que se conformaban, los mayeque 25 tomaron ocasión para "rebelarse" a sus Señores naturales y sacar partido, haciéndoles perder el dominio sobre ellos, la renta que les generaban y hasta las mismas tierras. $Y$ "...se les alzan con ellas (las tierras) los mayeque, porque dicen que son suyas y de sus pasados, y como no se entiende la forma en que las tenían, les vale lo que intentan y salen con ello, y así quedan los Señores perdidos y destruidos y acobardados..." (ZORITA, 1941, p. 154).

Un fenómeno más que se presentó al interior de las comunidades indígenas fue el surgimiento de actores sociales de "cambio o incidencia" originarios de las mismas, que buscaban promover transformaciones estructurales. Así, dichos actores "...bautizaban su ambición para los destruir (a los macehualtin) y subir ellos con celo de ayudar al común, y sacaban al común las entrañas, y decíanles que era para los defender y librar de sus Señores, y procuraban que no los obedeciesen..." (ZORITA, 1941, p. 96 - el paréntesis es mio), de lo cual hubo grandes disidencias y hasta conformación de bandos al interior de tales comunidades.

Con ello se gestó también el estereotipo que otorgaba a los indígenas un velo de pureza, inocencia y docilidad que determinaba la necesidad de la entrada de un agente externo a la comunidad para levantarlos y organizarlos para protestar, para "liberarlos de su opresión". Así, los "renteros y mayeques" que aún no se habían sublevado, aprovecharon para disminuir las cargas tributarias que debían a sus Señores y hasta para alzarse con toda la tierra que les era arrendada 26 .

Ante tales convulsiones los antiguos tlatoque convertidos en caciques o gobernadores, también optaron por convertirse ellos mismos en explotadores y especuladores de las tierras en manos colectivas del

\footnotetext{
${ }^{25}$ Sector de la población indígena precolombina sin tierras, que rentaba su mano de obra fluctuante (CARRASCO, 1996).

${ }^{26}$ Un factor importante que queda detrás de estos movimientos transformadores, es el que los pueblos "libres" o repúblicas de indios proporcionaban importantes ingresos fiscales tanto a la Corona como a la Iglesia, de ahí el interés de la administración colonial por favorecer y hasta promover dicho fenómeno de disolución de la antigua organización social. Otras veces fueron curas párrocos que compenetraban intereses con la comunidad y por ello procuran protegerles y defender sus derechos. La República de Indios nació para fragmentar el antiguo señorío. En tal caso, aquellos dos beneficiarios llegaron a convertirse en aliados y protectores de estos sectores indígenas, al menos durante esta etapa de transición en que eran aniquilados el poder y los privilegios de la antigua nobleza indígena.
} 
común y, así, ser partícipes de la rapiña en que cayeron los medios de producción 27 . Pero con el cargo público venían los castigos por mal servicio que imponía la Audiencia, así como la remoción del nombramiento, a los cuales muchos se hacían acreedores a partir de falsos testimonios sobre tiranías y malas administraciones, imputados por aquellos que se dedicaban a revolver a la gente, y hasta por sus antiguos súbditos, entonces dicho cargo era otorgado a alguno de aquellos advenedizos o bien a un miembro de la propia comunidad, antes en calidad de gente del común ${ }^{28}$. Así, los antiguos señores de linaje "fueron quedando en la más absoluta pobreza y miseria".

La rebelión de los terrazgueros (que ya incluía a maceguales y mayeque) alcanzó inclusive a confrontar a funcionarios y autoridades virreinales, terratenientes y hasta a la propia Iglesia, a causa de abusos y despojos cometidos; donde las comunidades indígenas fueron favorecidas en tribunales por la corona española, la cual, fallaba varias veces en su favor o procuraba remediar los problemas, por lo que pronto, y con su política de "liberación" para la conformación de las Repúblicas de Indios, se ganó la lealtad y estimación de los indígenas involucrados en este fenómeno.

El concepto "libertad" apareció entonces relativo al fin de los servicios personales, del pago de tributo y del reconocimiento de privilegios a las élites nobles indígenas, y constituyó un deseo infundido en el anquilosamiento del dominio colonial; proceso de ideologización que confrontó antiguas partes complementarias, dando como resultado el cambio jurídico en la posesión-ocupación de la tierra y en las condiciones objetivas de subsistencia29.

\footnotetext{
${ }^{27}$ López Serralangue señala la aparición de una nobleza indígena "advenediza" estimulada por los españoles, que en el contexto de este fenómeno, que con la paulatina declinación de la nobleza indígena de linaje durante el siglo XVI, entró a ocupar los puestos de dirigencia vacantes en beneficio de sus padrinos, quienes les manejaban a su antojo (apud CASTRO GUTIÉRREZ, 2004).

${ }^{28}$ Todo esto constituye lo que el propio Katz denominó como "una especie de reforma agraria colonial", asignación de tierras en calidad de propiedad comunal a sectores de la población indígena no privilegiada que en la época prehispánica carecía de éste y otros bienes, o condiciones de subsistencia mejor respaldadas jurídicamente como la ocupación de una tierra. De esta forma, mayeque y esclavos principalmente, fueron instalados en pueblos por los españoles, donde obtuvieron de éstos los derechos a que antes no eran sujetos (KATZ, 1998, p. 78).

${ }^{29}$ Es preciso ponderar el impacto, como bien apunta Castro Gutiérrez, que la mortandad masiva experimentada en gran parte de Mesoamérica a causa de las epidemias provocó en la cultura, al llevarse primero a los miembros más ancianos de la comunidad, llevándose consigo gran parte de los conocimientos acumulados durante milenios y que dependían de la transmisión oral para pasar a las siguientes generaciones, lo que representaba una ruptura importante con aquel mundo (CASTRO
} 
Así, los linajes gobernantes siguieron perdiendo sus privilegios en la medida en que las rebeliones de terrazgueros protagonizaron nuevos capítulos de la historia social novohispana, los cuales se multiplicarían para el siglo XVIII, buscando liberarse del sometimiento económico y político, y establecerse como pueblos independientes con tierra propia (MENEGUS, 2005, p. 65) y plena jurisdicción civil sobre asuntos comunitarios, contexto en el que se comenzaría a dar a partir de mediados del siglo XVII la recuperación demográfica indígena en la Nueva España.

Hay que señalar que la pérdida de derechos gubernativos, de tierras, de poder económico y de la obediencia de los campesinos, sufrida por estos linajes, también estuvo relacionada con el incremento de las "rebeliones". Pero ello no significaría ni la emancipación de la población indígena, ni el fin de sus sufrimientos, ni la redención de sus demandas, pues el avance hacia el liberalismo económico, les enfrentaría nuevos procesos de opresión que les acarrearían hacia un progresivo y más acentuado deterioro. No obstante, la conformación de la identidad territorial, cultural y étnica bajo las figuras de las corporaciones (República de Indios), les brindaría la oportunidad de oponer nuevas estrategias de defensa y resistencia hacia la explotación, el despojo y la agresión de que seguirían siendo objeto durante todo el periodo colonial y más aún en el México republicano.

\section{Conclusiones}

Podemos considerar que a través del fenómeno de la rebelión de los terrazgueros, las comunidades indígenas encontraron los mecanismos para sobrevivir al proceso colonial como colectividades, derrocando por lo menos a uno de sus explotadores: el señor natural, en un campo de batalla principalmente jurídico. Sumado a esto, el shock colectivo por las defunciones masivas y la reinvención de las

GUTIERREZ, 2004, p. 53). Ante la persecución religiosa y cultural, los cambios desfavorables en la estructura social y política con el consecuente deterioro del papel desempeñado por las élites locales, y las presiones económicas derivadas de reformas administrativas, (la tenencia y explotación de la tierra), los indígenas se vieron frente a la incertidumbre del futuro y de su supervivencia, por lo que algunos se vieron impelidos inclusive a recurrir al amparo de mitos. 
comunidades bajo la figura de República de Indios conllevaría al verdadero fin de la era antigua, la de los Señores de linaje, aunque hay que señalar que la desaparición de aquellos no fue total, y muchos sobrevivieron hasta el siglo XIX con privilegios de linaje y otras prerrogativas.

La crisis colonial desatada con la sobreexplotación de las fuerzas productivas, generó una nueva sociedad que, frente a los reacomodos poblacionales denominados "congregaciones" y el marco jurídico que se les ofreció, proporcionaría a los pueblos y comunidades indígenas las condiciones para negociar un nuevo pacto social, el pacto colonial, con la supervivencia de su propio pensamiento y costumbres, mientras no representasen un peligro de subversión o de desvío hacia una orientación política amenazante para las autoridades coloniales; aunque la lucha por su supervivencia ante el "colonialismo" apenas había iniciado 30 .

Aquí comparto la categoría de "rebelión de los terrazgueros" de Castro Gutiérrez (2004) y la complemento con el apelativo de "popular", pues amén de la intromisión de una infinidad de agentes externos, picapleitos y de los intereses de la corona, es un hecho que el malestar popular impulsó incluso a las comunidades más pequeñas para aspirar a un estatus mejor dentro del orden colonial, ya sea bajo la figura de cabecera o de República de Indios, al amparo de grupos de abogados españoles que vivían de alentar o provocar litigios con estos objetivos (GIBSON, 2007, p. 58).

Así, durante los siglos XVI y XVII hubo una notable tendencia hacia la transformación progresiva de poblados sujetos en cabeceras (GIBSON, 2007 , p. 58), aspiraciones "independentistas" de carácter totalmente local que se vieron influenciadas, además de lo ya mencionado, por la aparición de la propiedad privada de la tierra y la remuneración económica de servicios particulares y terrazgo.

Ello también coadyuvó de forma decisiva al surgimiento del

\footnotetext{
${ }^{30}$ Señala Castro Gutiérrez que, en general hubo poca oposición abierta a las disposiciones políticas coloniales, ya sea por temor al castigo, por resignación o por el mismo estado de depresión colectiva, pero en general y durante o después de la "revolución", la principal modalidad de resistencia fue la huida, en un ambiente con los hispanos que llegó inclusive a la intimidación, a lo que los naturales respondieron con amenazas de violencia e invasiones colectivas de tierras, con dueño o no, etc. (CASTRO GUTIÉRREZ, 2004, p. 94).
} 
sentimiento de emancipación y rebeldía en los sectores populares de la sociedad, quienes tras haber sido importantes artífices de la destrucción de la hegemonía tributaria del excan tlatoloyan ${ }^{31}$, reaccionaban ahora en contra de los señores triunfantes y los sobrevivientes de la "Conquista", quienes buscaban contrarrestar sus pérdidas económicas por tener que compartir la producción con los colonizadores españoles.

Considero pues que el fenómeno hasta aquí visto puede ser catalogado como un proceso de etnogénesis, que no debe ser comparado con otras perspectivas conceptuales ni tipologías como etnias reconstituidas y resucitadas de otros contextos históricos (PÉREZ, 2001, apud BARTOLOMÉ, 2003, p. 175), pues lo visto aquí es una emergencia de maceguales y terrazgueros que buscaron renegociar las relaciones sociales de producción en el contexto del estado colonial, reinventándose jurídica y hasta culturalmente.

Podría asociarse a la revitalización étnica referente a dinámicas etnopolíticas modernas que proponen la construcción o reconstrucción de sujetos colectivos en términos étnicos, protagonizadas por grupos etnolingüísticos que perdieron o nunca tuvieron la experiencia de la movilización conjunta en pos de objetivos compartidos (BARTOLOMÉ, 2003, p. 175); más no pretendo que nuestros maceguales y terrazgueros hayan actuado totalmente organizados por objetivos comunes. Fue un proceso multiforme en que prevalecieron los agentes, indígenas y extranjeros, que convencían a comunidades enteras para adquirir su cabildo y gobierno, pero ello no resta importancia al contexto de malestar y oprobio sí fue general y detonante de tal fenómeno.

En la etnogénesis contemporánea, las culturas luchan por constituirse como colectividades, como sujetos colectivos para articularse con un estado en mejores condiciones políticas. Se trata de la creación de un nuevo sujeto histórico (BARTOLOMÉ, 2003, p. 176). Y precisamente eso fue la creación de las corporaciones colectivas indígenas, agrupadas por lengua, localidad y tierra, a partir de lo que reinventaron su ser, sin perder identidad ${ }^{32}$, consiguiendo una nueva

${ }^{31}$ Triple alianza entre México-Tenochtitlan, Tetzcoco y Tlacopan que dominaba Mesoamérica hasta 1521.

${ }^{32}$ El caso de algunas congregaciones de indios resulto en la reinvención de la identidad pues contenían a poblaciones de diversas filiaciones étnicas precolombinas supervivientes de las catástrofes demográficas. 
designación étnica, diferenciada a la históricamente constituida, actualizada en el "indio vasallo" novohispano, concepto que más tarde se convertiría en un lastre del colonialismo y nuevo objeto de oprobio y sometimiento.

Coincido en que como reconstrucción identitaria no hay una interpretación unívoca de la etnogénesis (BARTOLOMÉ, 2003, p. 177), y tampoco es este un claro caso de clandestinidad y resistencia ante una sociedad envolvente; aunque la resistencia pasiva y activa en el contexto colonial se ha considerado de muy diversas formas; pero indudablemente el instinto de autoconservación llevó a nuestros protagonistas a convertirse en corporaciones indígenas, a la conservación y transformación de sus culturas, y eventualmente de la memoria histórica que encierra poder político, social y simbólico en los hechos de crear y transmitir historia propia, por medio de adaptaciones creativas (HILL, 1996, apud GOOD y CORONA, 2011, p. 30) con las que las colectividades hacen frente a contextos adversos o de oportunidades $y$, gracias a lo cual, se convirtieron en lo que hoy conocemos como pueblos y comunidades indígenas, producto de aquel fenómeno sociopolítico que redibujó ontológicamente hablando al nuevo "ser" comunitario.

\section{Bibliografía}

BALANDIER, Georges. Antropología política. Buenos Aires: Ediciones del Sol, 2004.

BARTOLOMÉ, Miguel A. "Los pobladores del "Desierto": genocidio, etnocidio y etnogénesis en la Argentina". Cuadernos de Antropología Social, Buenos Aires, n. 17, p. 162-189, 2003.

BIORD CASTILLO, Horacio. Ser indios otra vez: exordio a los procesos de etnogénesis en Venezuela, en Presente y Pasado. Revista de Historia, v. 17, n. 34, p. 11-40, 2012. Disponível em: http://www.saber.ula.ve/bitstream/123456789/36476/1/articulo1.pdf . Acesso em: 02 dez. 2015.

BRODA, Johanna. Las comunidades indígenas y las formas de extracción del excedente: época prehispánica y colonial. In: Ensayos sobre el desarrollo económico de México y América Latina (1500-1975). México: FCE, 1979. p. 64. 
CARRASCO, Pedro. Estructura político-territorial del Imperio tenochca: la Triple Alianza de Tenochtitlan, Tetzcoco y Tlacopan. México: El Colegio de México/FCE, 1996.

CARRASCO, Pedro; BRODA, Johanna. Economía política e ideología en el México prehispánico. México: Nueva Imagen, 1978.

1982.

Estratificación social en la Mesoamérica prehispánica. México: INAH/SEP.

CASTILLO F., Victor. Estructura económica de la sociedad mexica, según las fuentes documentales. México: IIH/UNAM, 1972.

- Aspectos económicos en las fuentes de tradición indígena: Uso y aprovechamiento historiográfico (Ponencia presentada en el XLI Congreso Internacional de Americanistas). Estudios de Cultura Náhuatl, México, n. 12, IIHUNAM, 1976.

CASTRO GUTIÉRREZ, Felipe. La rebelión de los indios y la paz de los españoles. México: CIESAS/INI, 1996.

2004.

Los tarascos y el imperio español 1600-1740. México: UNAM-UMSNH,

COOK, Sherburne; BORAH, Woodrow. Ensayos sobre historia de la población: México y el Caribe. México: Siglo XXI, 1998.

FALLERS, Lloyd. Bantu bureaucracy: a century of. In: BALANDIER, Georges. Antropología política. Buenos Aires: Ediciones del Sol, 2004. p. 57-78.

GARCÍA CANCLINI, Nestor. ¿De qué estamos hablando cuando hablamos de lo popular? In: Antología sobre cultura popular $\mathbf{e}$ indígena $I$. México: DGCPI/CONACULTA, 2004.

GIBSON, Charles. Los aztecas bajo el dominio español 1519-1521. México: Siglo XXI, 2007.

GOOD, Catharine: CORONA, Laura (Org.). Comida, Cultura y modernidad en México: Perspectivas antropológicas e históricas. México: INAH/CONACULTA, 2001.

KATZ, Friedrich (Org.). Revuelta, rebelión y revolución: la lucha rural en México del siglo XVI al siglo XX. México: Editorial Era, 1998.

LOCKHART, James. Los nahuas después de la Conquista: Historia social y cultural de la población indígena del México central, siglos XVI-XVIII. México: Fondo de Cultura Económica, 1999. 
LEÓN PORTILLA, Miguel. Toltecayotl: aspectos de la cultura náhuatl. México: FCE, 1980

La filosofía náhuatl estudiada en sus fuentes. México: UNAM, 2006.

LÓPEZ AUSTIN, Alfredo. Cuerpo humano e ideología: las concepciones de los antiguos nahuas. UNAM: México, 1980.

Organización política en el Valle de México. México: UNAM, 1985.

MÁLISHEV, Mijail; SEPÚLVEDA GARZA, Manola. Teoría sobre etnia y etnogénesis de León Gumiliov. Dimensión Antropológica, México, v. 4, p. 113-131, 1995.

MENEGUS BORNEMANN, Margarita. Del señorío a la República de Indios: el caso de Toluca 1500-1600. México: CONACULTA, 1994.

MENEGUS BORNEMANN, Margarita; AGUIRRE SALVADOR, Rodolfo (Org.). EI cacicazgo en Nueva España y Filipinas. México: Centro de Estudios sobre la Universidad-UNAM-Plaza y Valdés, 2005.

MONZÓN, Arturo. El calpulli en la organización social de los tenochea. México: Instituto de Historia, UNAM, e Instituto Nacional de Antropología e Historia, 1949.

NAVARRETE LINARES, Federico. Los orígenes de los pueblos indígenas del valle de México: Los altépetl y sus historias. México: UNAM, 2011.

PÉREZ ROCHA, Emma; TENA, Rafael. La nobleza indígena del centro de México después de la conquista. México: INAH, 2000.

PERUSSET, Macarena. Un acercamiento a los procesos de etnogénesis en el Paraguay colonial. In: Gazeta de Antropología, n. 23, art. 12, 2007. Disponível em: http://hdl.handle.net/10481/7048 . Acesso em: 21 nov. 2015.

POMAR, Juan Bautista; ZURITA, Alonso. Relaciones de Texcoco y de la Nueva España. México: Salvador Chávez Hayhde, 1941.

REINA, Leticia (Org.). Las luchas populares en México en el siglo XIX. México: CIESAS, 1983.

Indio, campesino y nación en el siglo XX mexicano: historia e historiografía de los movimientos rurales. México: Siglo XXI, 2011.

SALOMA, Ana Ma. Tenencia y uso de la tierra en Xochimilco. In: BARRERA RUBIO, Alfredo (Org.). ANALTÉ: Modo de producción tributario en Mesoamrica. Mérida: Escuela de ciencias antropológicas/Universidad de Yucatán, 1984. v. 3.

SORIANO HERNÁNDEZ, Silvia. La lucha y resistencia indígena en el México colonial. México: CIMECH/UNAM, 1994. 
STAVENHAGEN, Rodolfo. Las clases sociales en las sociedades agrarias. México: Siglo XXI, 1969.

VALVERDE VALDÉS, María del Carmen (Org.). La resistencia en el mundo maya, México: IIFL-UNAM, 2007.

ZORITA, Alonso. Relación de la Nueva España. México: Cien de México/CONACULTA, 1999.

Recebido em: 08/10/2015* Aprovado em: 15/12/2015* Publicado em: 31/12/2015 